\title{
Research on carbon emission differences decomposition and spatial heterogeneity pattern of China's eight economic regions
}

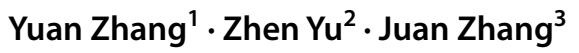 \\ Received: 23 August 2021 / Accepted: 30 November 2021 / Published online: 8 January 2022 \\ (c) The Author(s), under exclusive licence to Springer-Verlag GmbH Germany, part of Springer Nature 2021
}

\begin{abstract}
To explore the sources of regional carbon emission differences and the evolution characteristics of spatial heterogeneity pattern, this paper first calculates the corresponding carbon emissions according to the relevant statistical data of eight economic regions in China from 2005 to 2019. It analyzes the overall differences and temporal and spatial evolution characteristics of regional carbon emissions combined with the visualization method of GIS. Then, the total carbon emission difference is decomposed by the Theil index to find out the primary sources affecting the regional carbon emission difference. Finally, the driving factors affecting the spatial heterogeneity pattern of regional carbon emissions are studied with the help of the Geodetector method. The results show that (1) significant differences in carbon emissions among China's eight economic regions. The contribution rate of inter-regional and intra-regional differences of carbon emissions in different regions to the overall carbon emission difference is diverse. (2) Regional carbon emissions are affected by single driving factors and the interaction of two driving factors. The interaction has an increasing impact on the determinant of regional carbon emission spatial differentiation. (3) The factor detection results and interaction detection results, respectively, show that the level of energy consumption, industrialization, and technological development has always been the main driving factors affecting the spatial heterogeneity pattern of regional carbon emissions, and the critical interaction factors have multiple spatial superposition interaction effects. Therefore, regional carbon emission reduction should consider the national strategic objectives and own regional characteristics and implement differentiated emission reduction schemes.
\end{abstract}

Keywords Carbon emission · Differences decomposition · Driving factors · Geodetector method $\cdot$ Theil index

\section{Introduction}

The increase in carbon emissions caused by human activities is the leading cause of global warming. As the largest developing country, China has actively participated in global climate governance, put forward a series of binding emission reduction targets, and actively fulfilled the responsibility of a big government. In 2015, President Xi Jinping announced at

Responsible Editor: Philippe Garrigues

Zhen Yu

solseagull@163.com

1 School of Management, China University of Mining \& Technology (Beijing), Beijing, China

2 State Key Laboratory of Precision Measuring Technology and Instrument, Tianjin University, Tianjin, China

3 College of Architectural Engineering, Qingdao Binhai University, Qingdao, China the Paris conference that China would peak its carbon dioxide emissions in 2030 and carbon intensity would decline by $60-65 \%$ compared with 2005 . Non-fossil energy will account for about $20 \%$ of the primary energy consumption, and forest volume will increase by 4.5 billion cubic meters over 2005. On September 22, 2020, President Xi solemnly announced at the 75th session of the United Nations General Assembly that China would adopt more favorable policies and measures to ensure that carbon dioxide emissions reach the peak by 2030 and strive to achieve carbon neutrality 2060 (hereinafter referred to as "30.60") (Kou and Zhang 2021). In December of the same year, President Xi further announced at the Climate Ambition summit that the carbon intensity in 2030 would decrease by more than $65 \%$ compared with that in 2005, the proportion of non-fossil energy in primary energy consumption will reach about $25 \%$, the forest stock will increase by 6 billion cubic meters compared with that in 2005, and the total installed capacity of wind power and solar power will reach more than 1.2 billion 
kilowatts. This commitment has become a key driving force to promote the turning point of global climate governance. Still, it also means that China will take 30 years to complete carbon emission reduction that developed countries in Europe and America can achieve in 50-70 years (Wang and Zhang 2020). In addition, COVID-19 has changed the development pattern of the global economy, making lowcarbon recovery an essential area of the game between big countries. Therefore, how to achieve carbon neutrality in China has become an urgent problem to be solved. Although the EU's strategic roadmap to achieve greenhouse gas neutralization in 2050 proposed in 2019 can provide a multi-perspective reference for the realization of carbon neutralization in China, China cannot copy the EU's strategic roadmap, based on China's basic national conditions and different development stages (Smriti 2020). However, China's economic structure determines its vast energy consumption, and carbon emissions are closely related to energy consumption (Yang et al. 2020). And at this stage, China's main primary energy consumption is still coal, accounting for more than 50\%, so China's carbon emission reduction pressure is enormous. China's resource endowment, energy structure, industrial structure, and other aspects are significantly different from Western countries, so we can't copy the experience of western countries mechanically and need to find a carbon-neutral path suitable for China's national conditions (Chen et al. 2021a, b).

To achieve China's " 30.60 " carbon emission reduction target, our government plays a dual role of government and market. The pilot construction of the carbon market was started in 2013, and the national unified carbon market was officially launched in 2017. Due to the imbalance and disharmony of regional development, there are significant differences in economic development and energy efficiency among different regions. On this basis, the apportionment of carbon emission reduction responsibilities in different regions has become a hot topic in regional interests. To achieve China's regional carbon emission reduction goals, many scholars explore China's carbon emissions from different perspectives. Liu et al. (2021a, b, c) found out the main driving factors of carbon emissions of various regional transportation industries by analyzing the carbon intensity differences of China's regional transportation industries. Gao et al. (2021) used the input-output method to explore the impact of China's provincial large-scale population migration on trade, empirically analyzing the effect of population transfer and trade carbon transfer on regional carbon emissions and targeted suggestions for China's provincial carbon emission reduction. According to the calculation results, Nam and Jin (2021) calculated the impact of energy efficiency on carbon emissions and put forward targeted emission reduction suggestions. Liu et al. (2021a, b, c) summed the relationship between agricultural carbon emissions and economic development. Cui et al. (2021) estimated the impact of carbon sink on agricultural carbon emission by introducing the effect of carbon sink on carbon emission. It is not difficult to see that in many studies, there are more studies on the differences of carbon emissions in China's industries and fewer studies to explore the evolution and influencing factors of regional carbon emission differences, which is not conducive to the unification of China's national carbon market.

Due to China's vast territory, there are significant differences in resource endowment, economy, population, technology, and other development levels in different regions of China. In the process of formulating China's regional carbon emission reduction policies, we must fully consider the regional differences in carbon emissions and the influence of influencing factors. Therefore, based on the previous research methods, this paper selects eight economic regions of China's carbon emission evolution characteristics for analysis (specific regional division is shown in Fig. 1), which is helpful to provide more targeted suggestions for China's unified carbon market. Unlike the previous study (Zhang et al. 2021), this paper selects 17 primary fossil fuels in China's provincial end energy consumption from 2005 to 2019, which is more accurate than the previous eight fossil fuels. Then, the spatial and temporal evolution characteristics of regional carbon emissions are studied by decomposing and analyzing the differences of eight regional carbon emissions. This method is different from the traditional measurement method. It can measure the influence of a single driving factor and detect the interaction force of driving factors, which can better detect the main reasons that affect the regional carbon emission differences. This method has a particular immune function to collinearity, which makes the calculation results more accurate. And this paper helps provide more targeted suggestions for China's unified carbon market.

\section{Literature review}

\section{Carbon emission reduction targets}

In 2019, global energy carbon emission reached the highest level of 33.1 billion tons. Therefore, it is urgent to take adequate measures to make the greenhouse gas "net zero-emission," also known as carbon neutralization, that is to say, the greenhouse gas directly or indirectly generated by human beings should be balanced with the greenhouse gas removed by afforestation, energy conservation, and emission reduction (Salvia et al. 2021; Deng et al. 2021). The greenhouse gases in the atmosphere mainly include carbon dioxide, methane, and other gases. Still, considering that most greenhouse gases come from the combustion of fossil fuels, this paper particularly considers carbon dioxide emissions. To achieve the goal of 
Fig. 1 Division of China's eight major economic regions
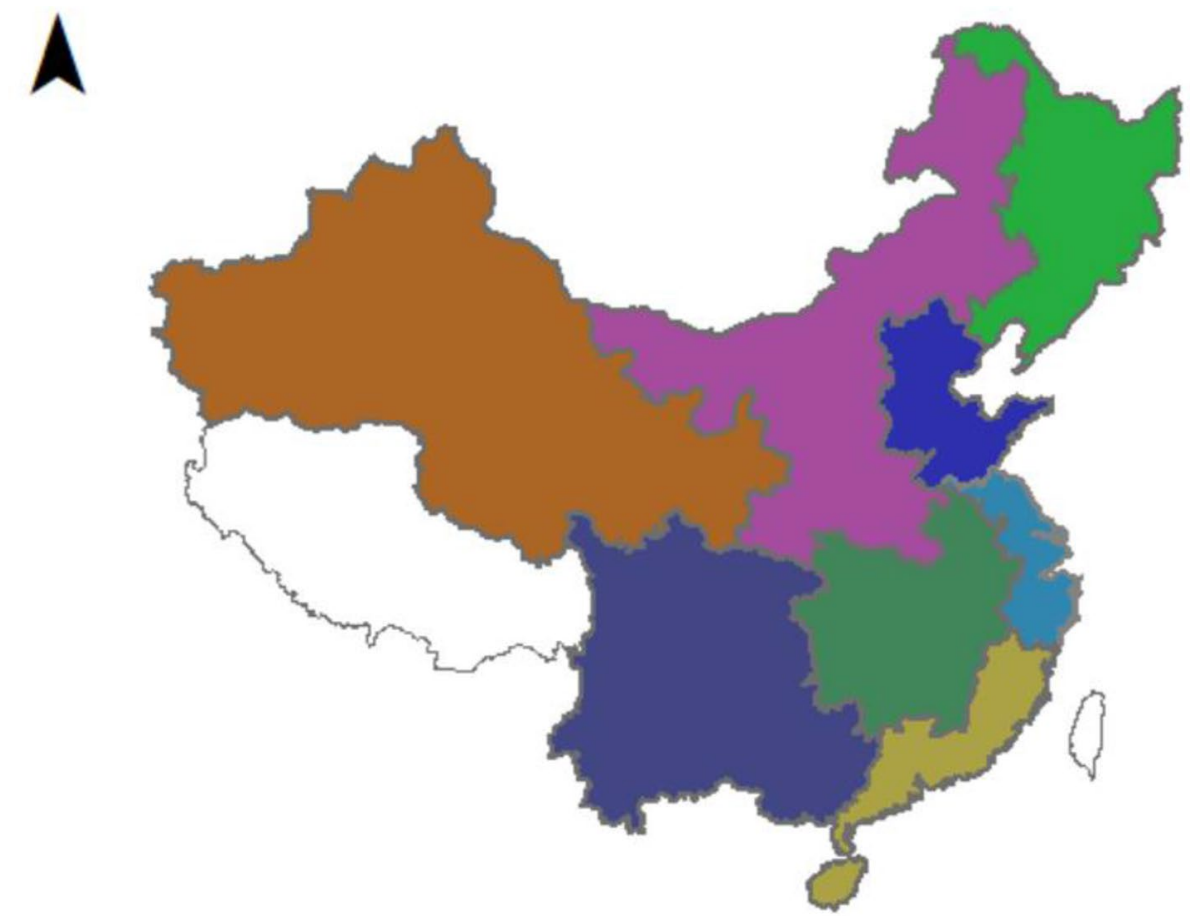

1,000

Kilometers
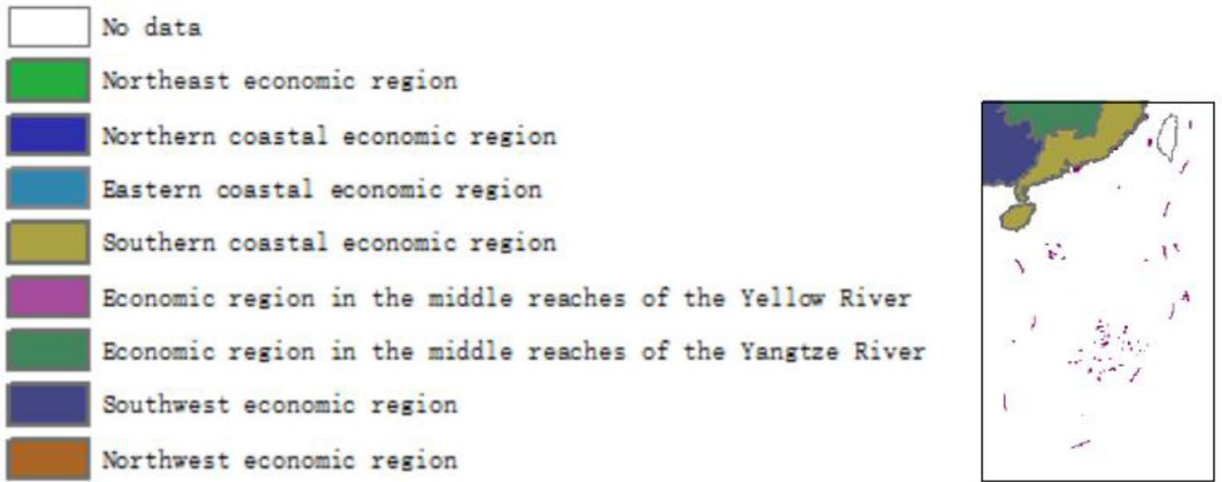

carbon neutralization in 2060, carbon emission is equal to a carbon sink, so increasing the regional carbon sink has become the key to achieving the goal of carbon neutralization. Carbon sequestration mainly comes from carbon dioxide absorbed by forests and stored by carbon capture, utilization, and storage (CCUS) technologies. Scholars analyze the carbon sink capacity of different countries and regions and the influencing factors from the terrestrial carbon sink (Wang et al. 2020), ocean carbon sink (Ridge and McKinley 2021), forest carbon sink (Roberto et al. 2021), land carbon sink (Anders and Lars 2021), and other perspectives. The results show that regions with solid carbon sink capacity are more likely to become carbon refuges in the future. Due to the high cost of CCUS technology and the significant reduction of new energy power generation costs, the industry develops slowly and has high uncertainty (Liu et al. 2021a, b, c). Therefore, this paper selects the carbon sink capacity (forest carbon sink) as the influencing factor of the corresponding carbon neutralization emission reduction targets and does not consider CCUS and other technologies. China has made a clear commitment to increase the forest stock by 6 billion cubic meters by 2060, so the regional forest carbon sequestration capacity has become the key to achieving the "30.60" emission reduction target. Therefore, under the constraint of the "30.60" target, carbon sink capacity should be introduced as an essential index in studying carbon emission differences in different regions. As carbon 
dioxide emissions from fossil energy account for about $80 \%$ of greenhouse gas emissions, at least $40 \%$ of methane, and $30 \%$ of nitrogen oxides are generated by fossil energy, this paper selects the primary fossil fuel consumption to estimate carbon emissions.

\section{Decomposition of regional carbon emissions differences}

When setting regional carbon emission reduction targets, we should fully consider the demand for social development and economic growth for energy consumption. Because carbon intensity is a standardized indicator to measure the effect of regional carbon emissions, many scholars compare and analyze the carbon intensity of different countries and regions (Liu et al. 2019; Zhang et al. 2019). Spatial decomposition and inequality analysis are widely used to research climate change and carbon emission reduction (Chang et al. 2019; Rong et al. 2019). Spatial decomposition research can study carbon emission differences between different regions (Liu et al. 2017). In various investigations on spatial decomposition, Ang et al. (2016) proposed the multi-regional spatial difference index decomposition method, which has been widely concerned. Since then, many scholars have carried out in-depth exploration and application in practice (Chen et al. 2019a, b, c; Wang et al. 2018). In analyzing the differences in carbon emissions at different levels of provinces, regions, and countries, some scholars have studied the inequality of energy consumption and carbon emissions (Bianco et al. 2019; Clarke-Sather et al. 2011; Duro and Padilla 2006). Wang and Zhou (2018) studied the inequality of per capita energy consumption based on the Theil index method and quantified the determinants of carbon emission inequality. Chen et al. (2018) used the Theil index to quantify China's regional carbon emissions inequality and decomposed it into intra-regional and inter-regional disparities.

On the whole, the Gini coefficient and Theil index are the two most commonly used indicators to decompose regional differences. Still, regional differences cannot be decomposed entirely (Cowell 1980). This paper selects the Theil index to measure the differences in carbon emissions in different regions.

\section{Research methods on the drivers of carbon emissions}

Carbon emissions are affected by many factors. To meet the social and economical products of human production and life, index decomposition analysis (IDA) and structural decomposition analysis (SDA) are the two most common decomposition methods in previous studies (Wang et al. 2017; Hoekstra and Bergh 2003). The existing IDA methods are all based on Kaya identity. The influencing factors studied are interdependent so that the decomposition results will produce different decomposition conclusions with the change of decomposition form. Therefore, Vaninsky proposed a new exponential decomposition method GDIM method, which can overcome the above defects of the exponential decomposition method (Vaninsky 2014). With the international community's attention to climate change, IDA and SDA are widely used to analyze carbon emission factors (Fan et al. 2007; Zhang 2010). IAD also includes logarithmic mean division index (LMDI) and adjustment weight analysis method (AWD) (Ang 2005). Wang and Feng (2018) explored the influencing factors of industrial carbon emission from the regional and provincial levels using the LMDI method. They analyzed the decoupling index and its components in different regions. The results show that the change of energy structure has little impact on climate change; industrial activities affect energy consumption and significantly impact carbon emission. Ma et al. (2019) constructed the carbon emission decomposition model optimization of China's energy consumption from 2005 to 2016 using the LMDI decomposition method. The research results show that the rapid economic development, the acceleration of urbanization, and the improvement of energy consumption intensity have a significant positive impact on carbon emission production and put forward targeted suggestions for developing a low-carbon economy. Zheng et al. (2019) conducted an in-depth analysis of the seven socio-economic driving factors affecting China's regional carbon emissions by using the LMDI method. The results show that different regions' driving factors leading to carbon emissions change are significantly different due to different development stages. To achieve the goal of carbon emission reduction as soon as possible, it is urgent to cooperate with different regions.

At the same time, the IPAT model (Burcu and Recep 2020; Majeed et al. 2020) and STIRPAT model (Eduardo et al. 2021) are also widely used in the study of carbon emission factors and have achieved remarkable results. $\mathrm{Li}$ et al. (2019) analyzed the spatial effects of high-tech industry, economic growth, FDI, and other elements on carbon emissions in 30 provinces of China by constructing the STRIPAT-Durbin model of the spatial panel and explored the impact of economic development and industrial structure on carbon emissions. The results show that high-tech industry, FDI, and population size have significant spatial spillover effects on carbon emissions. Yang et al. (2021) explored the spatial impact of three different technological progress channels using the STIRPAT model. They obtained the impact of various technical progress channels on the carbon emissions of six industries in China. The results show that different technological progress channels on carbon emissions of different sectors have significant spatial 
correlations and differences. Li et al. (2021) analyzed the energy carbon emission data of 30 provinces in China from 2011 to 2017 using the STIRPAT model. The results show that the energy structure has a significant impact on carbon emission, and the energy structure has a more substantial effect on the carbon emission of resource-based provinces. In the existing research, geographic detector technology to analyze the mechanism of regional carbon emissions is more petite. Therefore, this paper explores and compares the influencing factors of carbon intensity change in China's eight economic regions using the geographic detector model, a new method to analyze the influencing mechanism of spatial heterogeneity pattern of carbon emission.

\section{Theoretical methods}

\section{Estimation of carbon emissions}

This paper calculates the carbon emissions of different regions according to the terminal energy consumption method. This paper selects the primary energy terminal consumption in the energy consumption balance table of 30 provinces and regions except for Tibet, Hong Kong, Macao, and Taiwan. Combined with the calculation method provided by Intergovernmental Panel on Climate Change (IPCC), the carbon emissions from different fossil fuel combustion can be estimated and summed up according to the carbon emissions caused by energy consumption. The equation (Eq. 1) is as follows:

$\mathrm{CE}_{\mathrm{j}}=\sum_{\mathrm{i}=1}^{17} \mathrm{~A}_{\mathrm{ij}} \times \mathrm{NCV}_{\mathrm{i}} \times \mathrm{EF}_{\mathrm{i}} \times \mathrm{O}_{\mathrm{i}}$

In the above equation, $\mathrm{CE}_{\mathrm{j}}$ represents the carbon emission of fossil energy consumption in region $\mathrm{j}, \mathrm{A}_{\mathrm{ij}}$ means the consumption of the $i$ fossil fuel in area $\mathrm{j}, \mathrm{NCV}_{\mathrm{i}}$ represents the calorific value of the $\mathrm{i}$ fossil fuel, $\mathrm{EF}_{\mathrm{i}}$ represents the emission factor of the i fossil fuel, $\mathrm{O}_{\mathrm{i}}$ presents the oxidation rate of the $\mathrm{i}$ fossil fuel, and the correlation coefficient is shown in Table 1 (Shan et al. 2017; Sun et al. 2015).

\section{Estimation of regional carbon emission difference and its structural decomposition}

This paper uses the Theil index to measure the difference in regional carbon emissions, which Theil first proposed. It was first used to calculate the income differences between countries and later widely used in different levels of regional income differences (Cantore and Padilla 2010). The most significant advantage of the Theil index is that it can decompose the overall differences between regions into two parts: intra-regional differences and inter-regional differences. It is conducive to the statistics of the change trend and range of
Table 1 The correlation coefficient

\begin{tabular}{|c|c|c|c|}
\hline Energy type $(i)$ & $\begin{array}{l}N C V_{i} \\
\left(\mathrm{PJ} / 10^{4} \text { tonnes; }\right. \\
\left.10^{8} \mathrm{~m}^{3}\right)\end{array}$ & $\begin{array}{l}E F_{i}(\text { ton- } \\
\left.\text { neCO }^{2} / \mathrm{TJ}\right)\end{array}$ & Oxidation rate \\
\hline Raw coal & 0.21 & 96.51 & 0.93 \\
\hline Cleaned coal & 0.26 & 96.51 & 0.93 \\
\hline Other washed coal & 0.15 & 96.51 & 0.93 \\
\hline Briquettes & 0.18 & 96.51 & 0.93 \\
\hline Coke & 0.28 & 115.07 & 0.93 \\
\hline Coke oven gas & 1.61 & 78.8 & 0.99 \\
\hline Other gas & 0.83 & 78.8 & 0.99 \\
\hline Other coking products & 0.28 & 100.64 & 0.93 \\
\hline Crude oil & 0.43 & 73.63 & 0.98 \\
\hline Gasoline & 0.44 & 69.3 & 0.98 \\
\hline Kerosene & 0.44 & 71.87 & 0.98 \\
\hline Diesel oil & 0.43 & 74.07 & 0.98 \\
\hline Fuel oil & 0.43 & 77.37 & 0.98 \\
\hline $\begin{array}{l}\text { Liquefied petroleum } \\
\text { gas }\end{array}$ & 0.51 & 63.07 & 0.98 \\
\hline Refinery gas & 0.47 & 73.33 & 0.99 \\
\hline Other petroleum & 0.43 & 74.07 & 0.98 \\
\hline Natural gas & 3.89 & 56.17 & 0.99 \\
\hline
\end{tabular}

inter-regional and intra-regional differences and can reveal the respective impact on the overall differences. The value range of the Theil index is $[0,1]$. The smaller the value is, the smaller the regional difference is, and on the contrary, the greater the regional difference is. Based on previous studies, the Theil index and its structural decomposition of regional carbon emission differences are shown in the following equation (Eqs. 2-4):

$\mathrm{T}=\mathrm{T}_{\mathrm{BR}}+\mathrm{T}_{\mathrm{WR}}=\sum_{\mathrm{i}=1}^{\mathrm{n}} \frac{\mathrm{C}_{\mathrm{i}}}{\mathrm{C}} \ln \left(\frac{\mathrm{C}_{\mathrm{i}} / \mathrm{C}}{\mathrm{G}_{\mathrm{i}} / \mathrm{G}}\right)+\sum_{\mathrm{i}=1}^{\mathrm{n}} \frac{\mathrm{C}_{\mathrm{i}}}{\mathrm{C}}\left[\sum_{\mathrm{j}=1}^{\mathrm{m}} \frac{\mathrm{C}_{\mathrm{ij}}}{\mathrm{C}_{\mathrm{i}}} \ln \left(\frac{\mathrm{C}_{\mathrm{ij}} / \mathrm{C}_{\mathrm{i}}}{\mathrm{G}_{\mathrm{ij}} / \mathrm{G}_{\mathrm{i}}}\right)\right]$

$\mathrm{T}_{\mathrm{BR}}=\sum_{\mathrm{i}=1}^{\mathrm{n}} \frac{\mathrm{C}_{\mathrm{i}}}{\mathrm{C}} \ln \left(\frac{\mathrm{C}_{\mathrm{i}} / \mathrm{C}}{\mathrm{G}_{\mathrm{i}} / \mathrm{G}}\right)$

$\mathrm{T}_{\mathrm{WR}}=\sum_{\mathrm{i}=1}^{\mathrm{n}} \frac{\mathrm{C}_{\mathrm{i}}}{\mathrm{C}}\left[\sum_{\mathrm{j}=1}^{\mathrm{m}} \frac{\mathrm{C}_{\mathrm{ij}}}{\mathrm{C}_{\mathrm{i}}} \ln \left(\frac{\mathrm{C}_{\mathrm{ij}} / \mathrm{C}_{\mathrm{i}}}{\mathrm{G}_{\mathrm{ij}} / \mathrm{G}_{\mathrm{i}}}\right)\right]$

Among them, $T$ represents the overall Theil index of regional carbon emissions, $T_{B R}$ and $T_{W R}$ represent the interregional and intra-regional differences of regional carbon emissions, respectively, $\mathrm{C}$ stands for the total carbon emissions of the country, $\mathrm{C}_{\mathrm{i}}$ means the carbon emissions of region $i, \mathrm{C}_{\mathrm{ij}}$ represents the carbon emissions of $j$ province in regioni.G, $\mathrm{G}_{\mathrm{i}}$, $\mathrm{G}_{\mathrm{ij}}$ represent the GDP of the whole country, regioni, and the province in region $i$, respectively. To further study the impact of inter-regional and intra-regional differences on the overall differences, the inter-regional and intra-regional contribution rates are defined as $\alpha$ and $\beta$. Among them, $\alpha$ is expressed by the 
ratio of the inter-regions Theil index to the overall Theil index, and it can be described as $\mathrm{T}_{\mathrm{BR}} / T$. Similarly, $\beta$ is expressed by the ratio of the intra-regions Theil index to the overall Theil index, which can be defined as $\mathrm{T}_{\mathrm{WR}} / T$.

\section{Study on the spatial heterogeneity pattern of regional carbon emissions}

In the past, LMDI and STIRPAT are the main methods to analyze the influencing factors of carbon emissions. In contrast, less research on the influence of different driving factors on carbon emissions using geographic detector technology. The geographic detector technology is a statistical method to detect spatial differentiation and identify its driving characteristics. Spatial stratified heterogeneity (abbreviated as spatial differentiation or regional heterogeneity) refers to the geographical phenomenon that the intra-level variance is less than the inter-level variance, such as regional economic differences and urban-rural differences, which is a significant feature of spatial data. The core is to assume that an independent variable has a significant impact on the dependent variable, so the spatial distribution of the independent variable should be highly similar to the spatial distribution of the dependent variable(Wang and Li 2010; Wang and Hu 2012).

GeoDetector can detect the numerical and qualitative data and see the interaction of two factors on the dependent variable. Specifically, through the spatial layered superposition analysis of the same region, the size and direction of the statistic $q$ value are used to judge whether the independent variable is the main driving factor of the dependent variable. Then, according to the multiple spatial superposition analysis of independent and dependent variables, the critical interaction factors of the dependent variable's spatial differentiation are explored by the interaction factor $q$. Compared with classical statistics, this method does not need to make a pre-determined assumption of sample distribution and has the immune function to multicollinearity. It also breaks through the traditional econometric model, which is limited to variable multiplication when exploring the interaction effect and detects the interaction effect between variables more accurately through spatial superposition technology (Wang and Xu 2017; Zhao and Wu 2018). This paper analyzes the influence degree and interaction of driving factors of regional carbon emission spatial differentiation based on factor detection and interaction detection. The model equation is as follows:

$P_{D, U}=1-\frac{1}{n \delta_{U}^{2}} \sum_{i=1}^{m} n_{D, i} \delta_{U_{D, i}}^{2}$

where $P_{D, U}$ represents the detectability index of influencing factors of regional carbon emissions, $n$ represents the number of study areas, $n_{D, i}$ represents the number of provinces in sub-region $D$, and $m$ represents the number of layers of a driving factor. This paper uses the natural breakpoint method in ArcGIS software to reclassify the five selected driving factors, and the numerical variables are changed into type variables. $\delta_{U}^{2}$ and $\delta_{U_{D, i}}^{2}$ represent the variance of the independent variable in the whole study area and sub-region D, respectively. The value range of $q$ is $[0,1]$. The larger the value of $q$, the greater the effect of this factor on the spatial differentiation of regional carbon emissions. When $q=0$, it shows that the spatial differentiation of regional carbon emissions is not affected by this factor.

\section{Data sources and processing}

Considering the reliability and availability of the data, this paper selects the relevant data of 30 provinces, autonomous regions, and municipalities (except Tibet, Hong Kong, Macao, and Taiwan) in China from 2005 to 2019. In this paper, the total carbon emissions generated by 17 kinds of end energy consumption, the proportion of the non-agricultural population (UR), per capita GDP (PGDP), regional gross industrial product (GIP), energy consumption intensity (ECI), forest stock (FS), total technology turnover (TT), and total import and export trade (IET) are used to express the regional carbon emission level, urbanization level, residents' living standard, industrialization level, energy consumption level, green development level, technological development level, and degree of opening to the outside world. The relevant data are from China Statistical Yearbook (2006-2020), China Energy Statistical Yearbook (2006-2020), China Population, and Employment Statistical Yearbook (2006-2020), and National Forest Resources Statistics (2006-2020). In order to ensure the consistency and comparability of the data, the GDP and industrial added value are selected 2005 as the base year, excluding the impact of price fluctuations and other factors. To estimate carbon emissions, 17 main end-use energy consumption varieties are chosen and combined with the appropriate estimation methods provided by IPCC. The measure of forest carbon sequestration is based on Yang et al. (2019). The volume method is selected to estimate the forest volume, represented by VF, and the relevant conversion coefficient refers to the relevant value in IPCC. The forest resources volume converted to biomass volume coefficient is 1.9 , which is expressed by $\alpha$. The conversion coefficient of biomass to biomass was 0.5 , which is represented by $\beta$. The conversion coefficient of dry biomass weight to carbon sequestration is 0.5 , which express by $\gamma$. The conversion coefficient of carbon sequestration of understory vegetation is 0.95 , described by $\delta$. The conversion coefficient of carbon sequestration is 1.244 , defined by $\varepsilon$. So the calculation formula of carbon sink in different regions can be expressed as $\mathrm{VF}=(1+\delta+\varepsilon) \alpha \beta \gamma$. 


\section{Empirical analysis results}

\section{Visual analysis of the regional carbon emissions}

To visually display the changing trend of the overall difference of carbon emissions in different regions, this paper calculates the total carbon emissions in different regions from 2005 to 2019 according to the calculation method provided by equation (Eq. 1). It then draws the carbon emission distribution maps of China's provinces in 2005 ,
2010, 2015, and 2019 with the help of ArcGIS software combined with the visualization method provided by the GIS (Fig. 2). It can be seen from Fig. 2 that in 2005, Shandong province had the highest carbon emission, with a carbon emission of 492.6 million tons, while Qinghai province had the lowest, with a carbon emission of only 26.4 million tons. By 2019, Shandong's carbon emissions have reached 927.7 million tons, nearly double that of 2005. On the whole, carbon emissions show a trend of increasing from west to east, and the carbon emissions

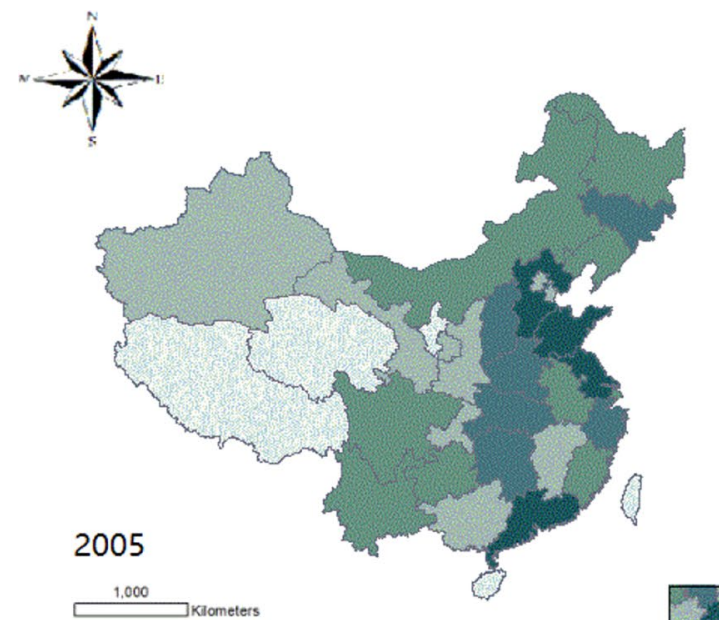

1,000 Kilometers

$0.000000-4775.799805$

$8256.049805-11491.700195$

$13074.400391-18227.500000$

$20069.300781-29386.400391$

$35244.101563-49263.601563$
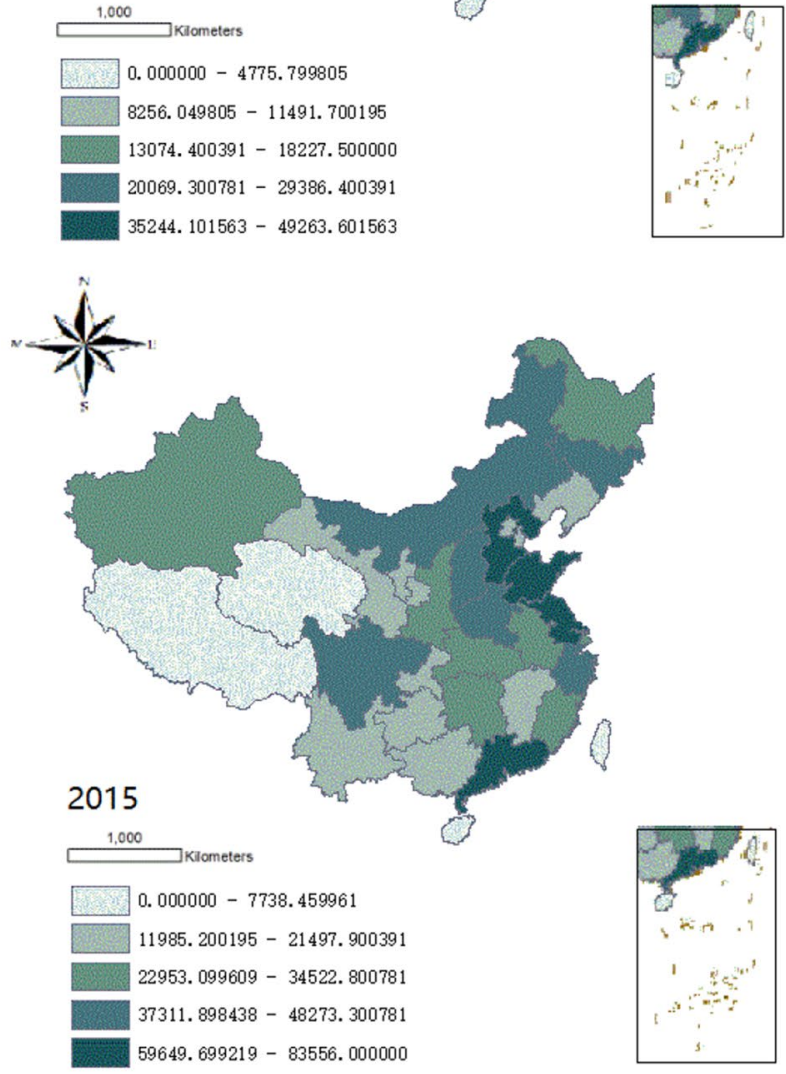

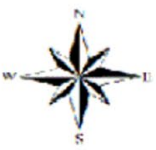

2010
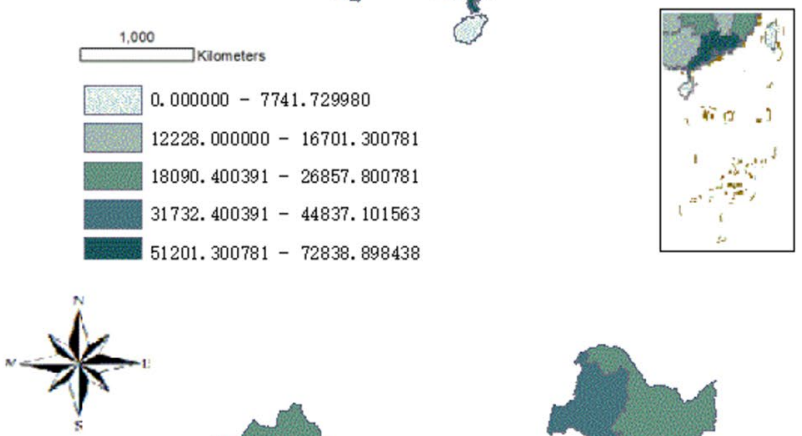

2019

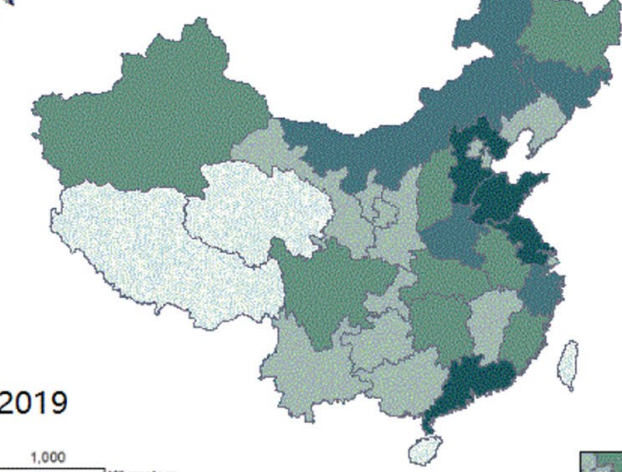

$0.000000-8566.240234$

$15620.500000-27744.800781$

$29914.599609-41041.898438$

45950.699219 - 56641. 000000

$71056.203125-92766.500000$

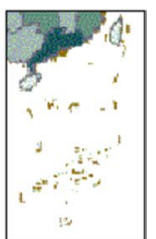

Fig. 2 Visualization results of provincial carbon emissions from 2005 to 2019 
of all provinces increase gradually over time. It can be seen that the carbon emissions of the eastern and northern coastal areas with the relatively developed economy are generally higher. In comparison, the carbon emissions of underdeveloped regions such as NWER and SWER are relatively lower.

\section{Calculation and decomposition results of the overall difference of regional carbon emissions}

Although the visualization method can directly reflect the differences in carbon emissions in different regions, the causes and evolution of the differences need to be further studied with the help of the Theil index method. According to the calculation method provided by equation (Eqs. 2-4), the Theil index and its decomposition results of the eight economic regions from 2005 to 2019 are calculated, as shown in Fig. 3. It can be seen that the overall difference of regional carbon emissions shows an upward trend of "up-down-up" fluctuation, with the fluctuation range of $0.44-0.58$. It also can be seen that the overall difference increased slowly from 2005 to 2013 and decreased slightly in 2014 and 2015. The root cause was establishing the national carbon market in 2013, which led to narrowing regional carbon emissions differences in 2014. From 2016 to 2019, the overall difference began to rise and fluctuate, which shows that the overall carbon emissions at the regional level still have a strong expansion trend, closely related to the differences in regional resource endowment and economic structure energy structure.

During the study period, the overall differences, the interregional differences, and the intra-regional differences of the eight economic regions' carbon emissions are shown in Fig. 4. From Fig. 4a, it can be seen that there are apparent differences in the overall carbon emissions in different regions, among which the overall carbon emissions differences in ERMRYR is the largest and shows a fluctuating upward trend, rising from 0.102 in 2005 to 0.130 in 2019, followed by the increase of 0.083 in 2005 in the northern coastal areas to 0.088 in 2019. This shows that more efforts will be needed in the future to reduce carbon emissions in the region. The SCER and SWER decreased slightly from 0.0561 and 0.054 in 2005 to 0.0560 and 0.033 in 2019, respectively. As shown in Fig. 4b, the intra-regional differences between the northern coastal areas and the middle reaches of the Yellow River are the largest. The regional differences in the NCER showed a fluctuating upward trend, while the regional differences in the middle reaches of the Yellow River showed a slow upward trend. The regional differences in carbon emissions in NEER, ERMRYTR, and SWER showed a fluctuating downward trend, indicating that these regions have achieved phased results in carbon emission reduction. The carbon emission difference in the ECER is the largest, rising from 0.0025 in 2005 to 0.117 in 2019. It can be seen from Fig. $4 \mathrm{c}$ that the carbon emission difference between regions fluctuates wildly. The ECER and the NEER are the regions with an enormous carbon emission difference, and the NEER has the most considerable change range, rising from 0.029 in 2005 to 0.073 in 2019, which has increased $151.5 \%$. The inter-regional differences in the middle reaches of the ERMRYTR, NEER, and NCER showed a fluctuating upward trend, while the other four areas showed a slight downward trend.

To further analyze the impact of inter-regional and intraregional carbon emission differences on the overall regional differences, this paper further calculates the proportion of inter-regional and intra-regional Theil index in the overall Theil index according to the result calculated in the previous
Fig. 3 The overall difference of carbon emissions and its decomposition results in China

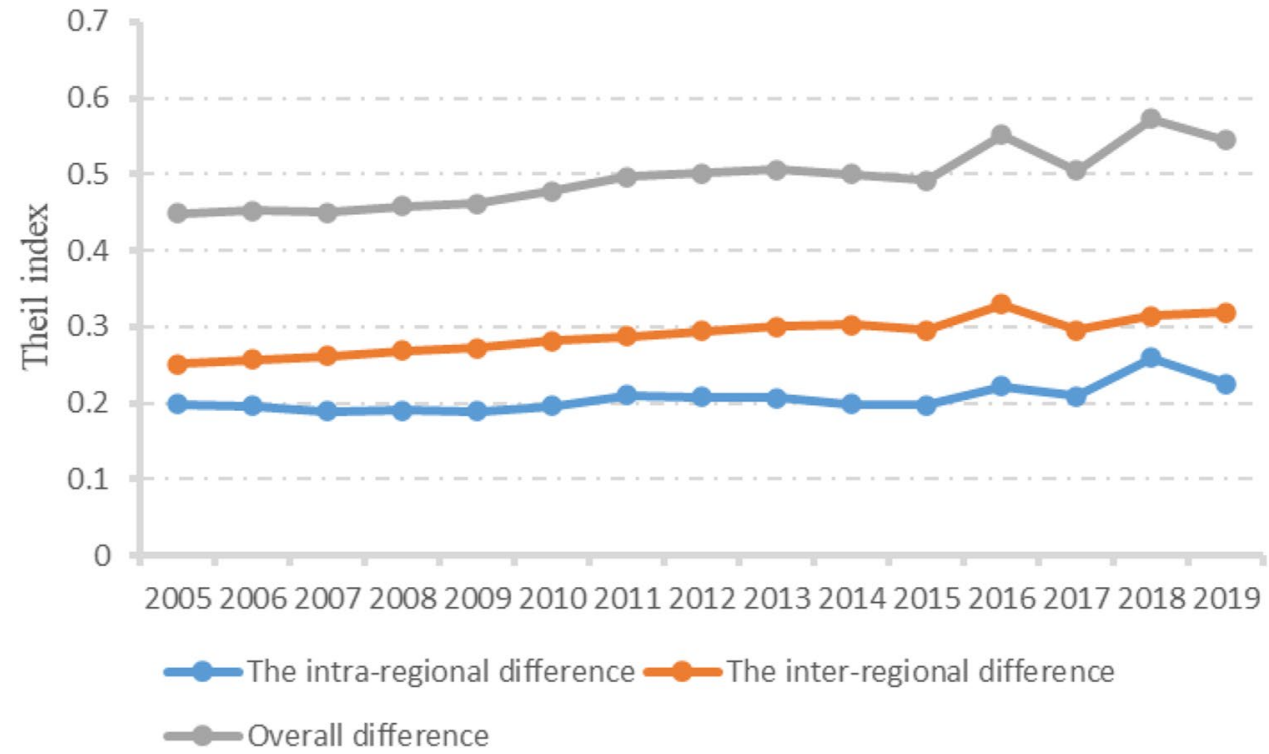


a)

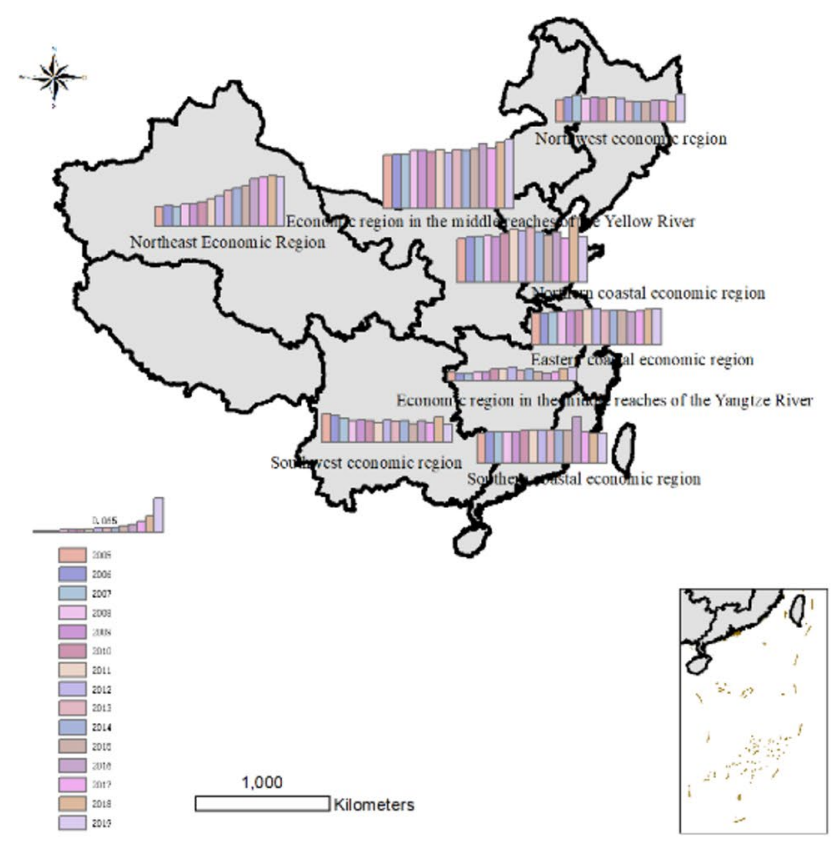

b)

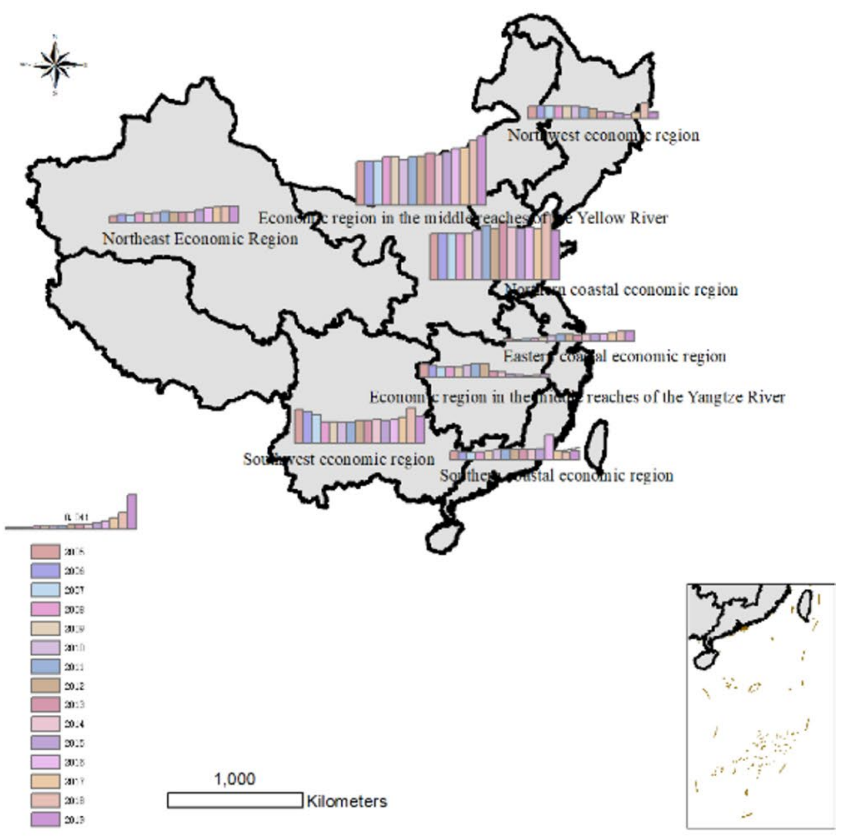

c)

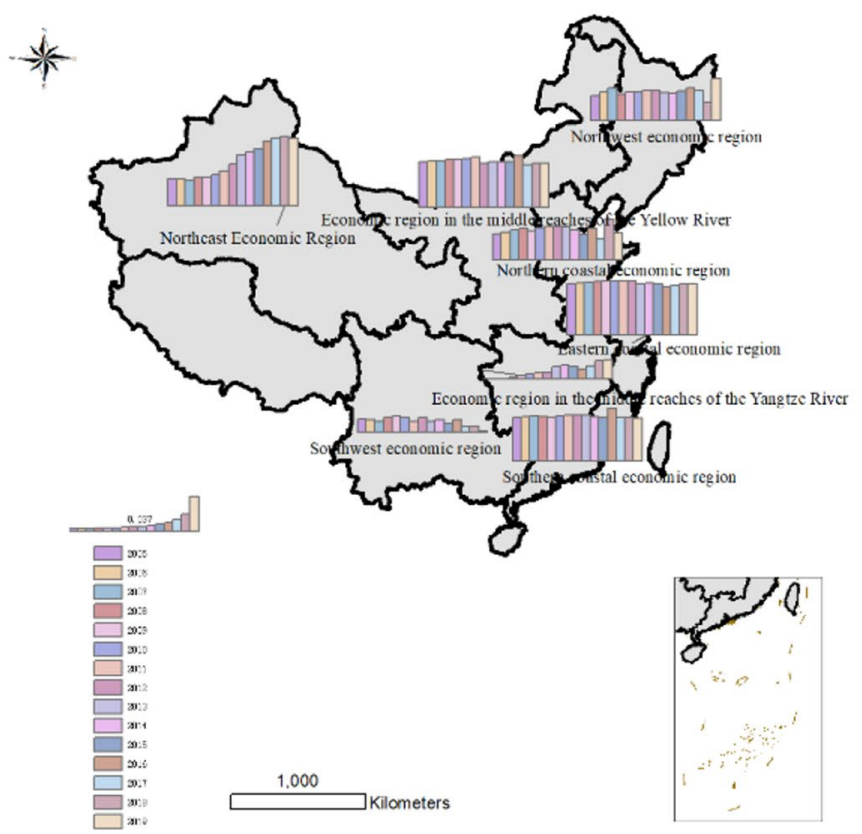

Fig. 4 Overall carbon emission differences and its decomposition results in China's eight economic regions. Note: a) Overall differences. b) The intra-regional difference. c) The inter-regional difference

section (data resource: Fig. 3). It is used to analyze interregional and intra-regional carbon emission differences to the overall regional carbon emission differences in different years and regions (Table 2). It can be seen that the contribution rate of inter-regional differences shows a slight upward trend during the study period in 2005-2019, while 


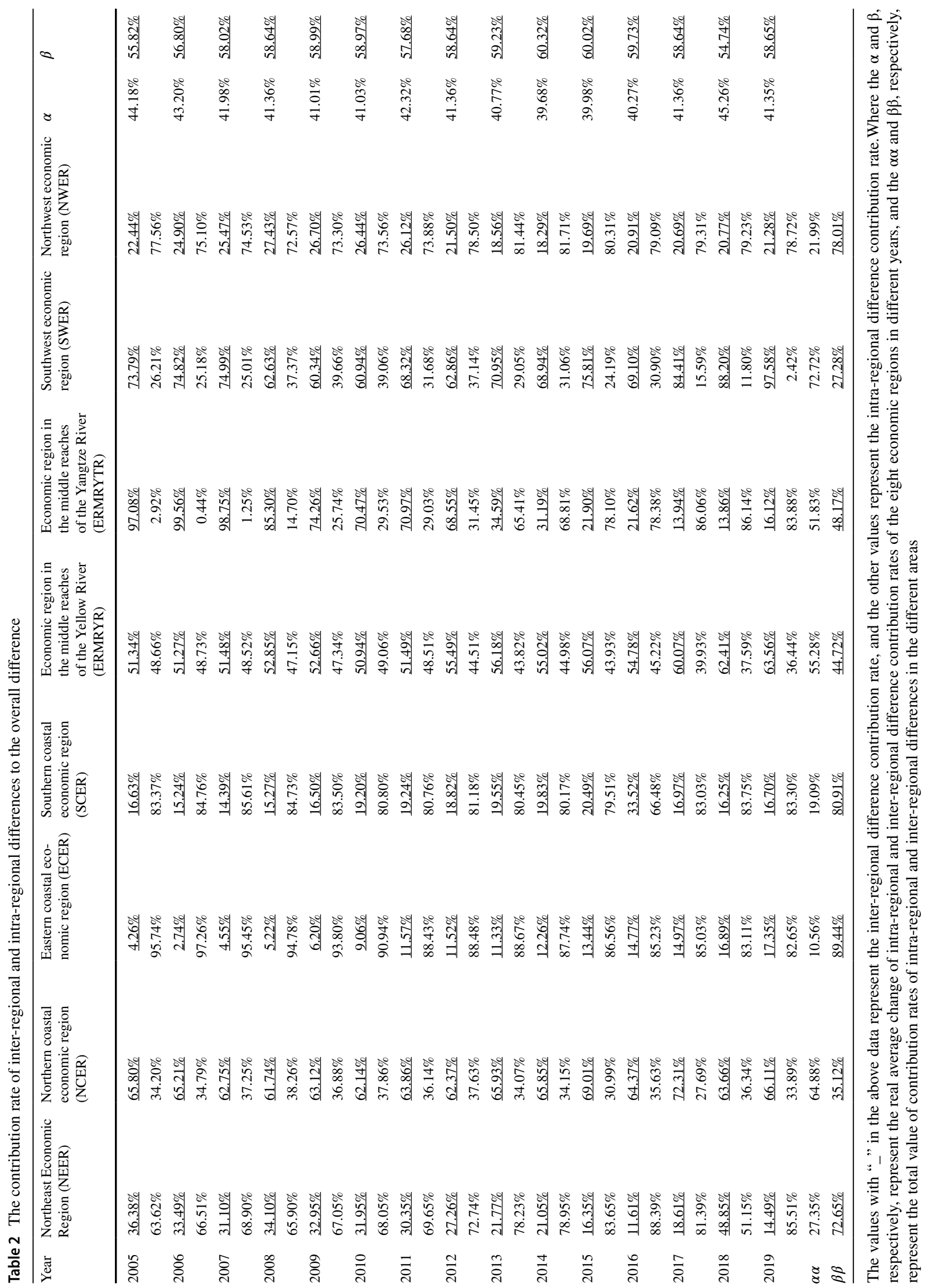


the contribution rate of intra-regional differences shows a slight downward trend, rising (decreasing) from $55.82 \%$ and $44.18 \%$ in 2005 to $58.65 \%$ and $41.35 \%$ in 2019 , respectively. From the average regional carbon emission difference, the carbon emission difference of NEER, ECER, SCER, and NWER are mainly caused by inter-regional differences. In contrast, intra-regional differences mainly cause the carbon emission difference of NCER, ERMRYR, ERMRYTR, and SWER. The massive difference in regional carbon emission is reflected in the significant difference between regions and largely depends on the gap among provinces in the region.

\section{Analysis on spatial differentiation pattern of regional carbon emission}

\section{Factor detector results}

The Geodetector method is based on cross-section data. This paper selects 2005 as the initial year and finally chooses 2005, 2010, 2015, and 2019 for analysis. Combined with the previous theoretical, the driving factors influencing the spatial differentiation of regional carbon intensity are detected and analyzed using Geodetector software, and the results are shown in Fig. 5.

(1) Overall, there are significant differences in the action intensity and development trend of the driving factors of regional carbon emission spatial differentiation in different periods. It can be seen from the factor detection results that the statistical value q of energy consumption level fluctuates between 0.74 and 0.82 , which has been in the prominent position affecting the regional carbon emission difference. However, from the perspective of average growth rate, this is the only driving factor with negative growth in the level of decisive power, which shows that with the continuous optimization of national energy structure, the level of energy consumption is gradually improved, and the impact of energy consumption intensity on carbon emission is decreasing. Among the other influencing factors, industrialization, economic development, and technological development are also more significant. On the contrary, although the level of urbanization, the level of green development, and the level of opening to the outside world have relatively small determinants of regional carbon emission differences, their corresponding growth rates are as high as $31.91 \%, 133.01 \%$, and $34.33 \%$ respectively, indicating that the determinant difference of various driving factors affecting regional carbon emission differences is gradually narrowing.

(2) From the perspective of time series, the order of influence degree of each driving factor in 2005 is $\mathrm{q}(\mathrm{ECI})>\mathrm{q}(\mathrm{GIP})>\mathrm{q}(\mathrm{TT})>\mathrm{q}(\mathrm{PGDP})>\mathrm{q}(\mathrm{IET})>\mathrm{q}(\mathrm{UR})>\mathrm{q}(\mathrm{FS})$. Among them, the values of $\mathrm{q}(\mathrm{ECI}), \mathrm{q}(\mathrm{GIP})$, and $\mathrm{q}(\mathrm{TT})$ are as high as $0.8104,0.3970$, and 0.3540 , respectively, which is much higher than other driving factors. Although the above main driving forces were still in the leading position in 2010, the value of q decreased to a certain extent. The decisive power of green development level, urbanization level, and opening-up level increased. In 2015, the decisive power of urbanization and technological development levels increased significantly, from 0.0765 and 0.1210 in 2010 to 0.1270 and 0.2600 in 2015 , with an increase of $66.07 \%$ and $114.82 \%$, respectively. Until 2019, the urbanization level will be stable at 0.1207 , an increase of $112.44 \%$ compared with 0.0568 in 2005, and the $q$ value of the green development level will reach 0.08619 , an increase of $187.82 \%$ compared with 0.0299 in 2005. This shows that although the $q$ value of both is relatively small compared with other factors, over time, the impact of urbanization level and green development
Fig. 5 Results of geographic factor detection

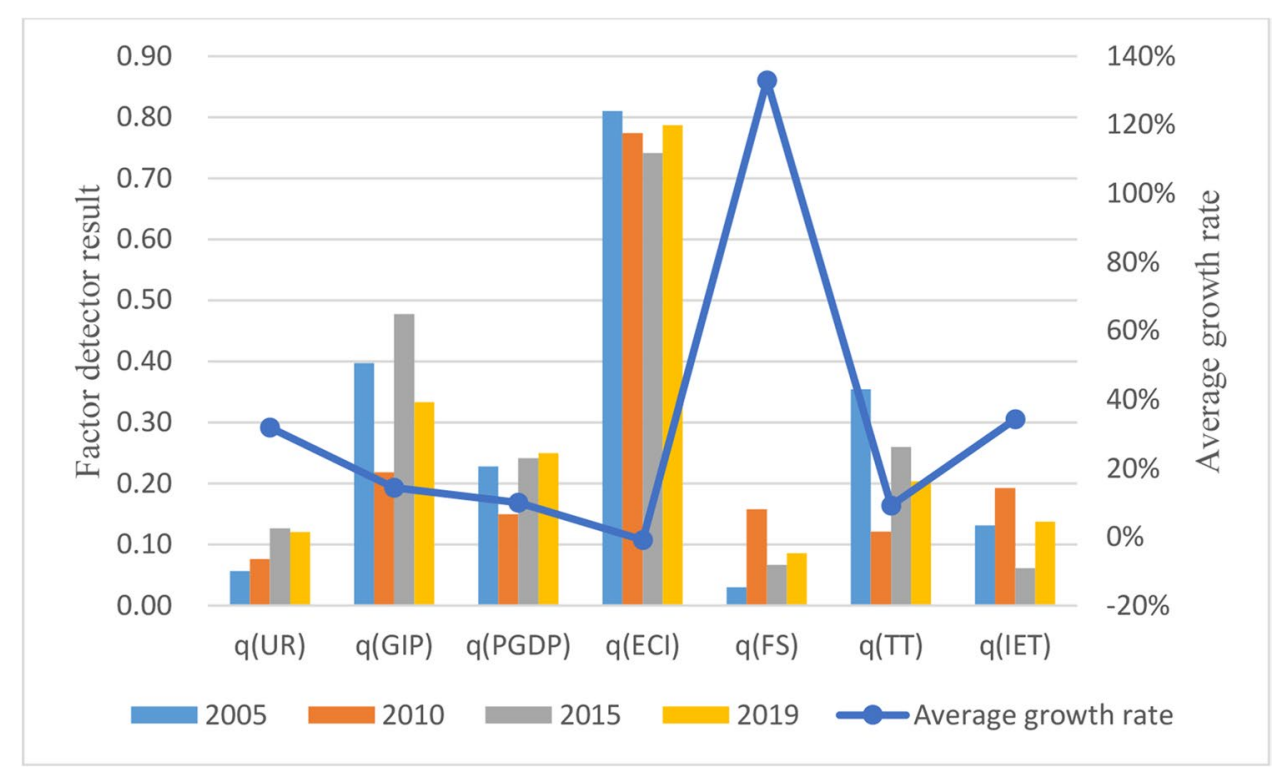


level on carbon emission is increasing, which should be paid attention to.

(3) From the changing trend of the action intensity of single driving factors, the urbanization level has increased steadily since 2005 , reached the highest value of 0.1270 in 2015, and decreased slightly to 0.1207 in 2019, which shows that there is an inverted " $U$ " relationship between the urbanization level and carbon emission level, that is, when the urbanization rate rises to a certain extent, with the increase of urban population, carbon emissions have decreased. Rapid urbanization can promote the accumulation of capital, labor, and other factors, promote the rapid growth of consumer demand, significantly increase the energy consumption demand, and lead to the rapid rise of carbon emissions. With the urbanization level reaching a certain level, the centralized utilization of resources can improve the resource utilization rate and reduce carbon emissions. This conclusion is similar to the results of Chen et al. (2019a). With the progress of technology and the continuous optimization of energy structure, the decisive power of industrialization, energy consumption, and technological development on carbon emission is decreasing, but it still occupies an important position. The determinant of the level of opening to the outside world shows a fluctuating development trend, which is closely related to the significant fluctuation of regional resource endowment and import and export volume. According to the "siphon effect principle," areas with high economic development levels can promote local industries' aggregation, resulting in higher carbon emissions. Therefore, the level of economic growth largely determines the spatial differentiation of carbon emissions. However, under the constraints of global warming, the traditional high energy consumption and extensive economic development model will eventually change to a green and low-carbon development model, promoting the development of the economy to a low-carbon economy that reduces energy dependence. The statistical value q of the green development level in 2019 is 0.0862 . Although it has relatively little decisive power on the spatial differentiation of carbon emissions, with the attention of the international community to global climate issues and the constraints of China's "30.60" double carbon goal, green development level will become one of the essential factors to evaluate the level of regional carbon emission reduction.

\section{Interaction detector results}

The statistical $q$ values of interaction factors superimposed by the above seven driving factors are shown in Table 3. The results show that the determinants of each interactive factor on the spatial differentiation of carbon emissions are nonlinear enhancement relationships or two-factor enhancement relationships. Among them, $\mathrm{UR} \cap \mathrm{ECI}, \mathrm{GIP} \cap \mathrm{ECI}, \mathrm{PGDP} \cap \mathrm{ECI}, \mathrm{ECI} \cap \mathrm{FS}, \mathrm{ECI} \cap \mathrm{TT}$, and ECI $\cap$ IET have
Table 3 The interactive detection results

\begin{tabular}{|c|c|c|c|c|}
\hline Interaction detector & 2005 & 2010 & 2015 & 2019 \\
\hline UR $\cap$ GIP & 0.757 & 0.609 & 0.730 & 0.679 \\
\hline URกPGDP & 0.420 & 0.317 & 0.433 & 0.437 \\
\hline URกECI & 0.920 & 0.939 & 0.936 & $\underline{0.936}$ \\
\hline $\mathrm{UR} \cap \mathrm{FS}$ & 0.229 & 0.426 & 0.479 & 0.523 \\
\hline $\mathrm{UR} \cap \mathrm{TT}$ & 0.602 & 0.335 & 0.499 & 0.476 \\
\hline URกIET & 0.455 & 0.514 & 0.437 & 0.434 \\
\hline GIP $\cap P G D P$ & 0.770 & 0.452 & $\underline{0.658}$ & 0.745 \\
\hline GIP $\cap E C I$ & $\underline{0.838}$ & $\underline{0.907}$ & $\underline{0.889}$ & $\underline{0.863}$ \\
\hline $\mathrm{GIP} \cap \mathrm{FS}$ & 0.595 & 0.515 & 0.791 & 0.639 \\
\hline $\mathrm{GIP} \cap \mathrm{TT}$ & $\underline{0.662}$ & $\underline{0.386}$ & $\underline{0.761}$ & $\underline{0.582}$ \\
\hline 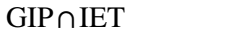 & 0.765 & 0.481 & 0.609 & 0.538 \\
\hline PGDP $\cap E C I$ & $\underline{0.841}$ & 0.830 & 0.865 & 0.941 \\
\hline PGDP $\cap F S$ & 0.570 & 0.417 & 0.481 & 0.459 \\
\hline $\mathrm{PGDP} \cap \mathrm{TT}$ & $\underline{0.618}$ & $\underline{0.321}$ & $\underline{0.416}$ & 0.568 \\
\hline PGDP $\cap I E T$ & 0.510 & $\underline{0.380}$ & 0.500 & 0.449 \\
\hline $\mathrm{ECI} \cap \mathrm{FS}$ & 0.885 & $\underline{0.814}$ & $\underline{0.842}$ & $\underline{0.872}$ \\
\hline $\mathrm{ECI} \cap \mathrm{TT}$ & $\underline{0.852}$ & $\underline{0.848}$ & $\underline{0.827}$ & $\underline{0.925}$ \\
\hline ECInIET & $\underline{0.907}$ & $\underline{0.871}$ & $\underline{0.801}$ & $\underline{0.902}$ \\
\hline $\mathrm{FS} \cap \mathrm{TT}$ & 0.695 & 0.477 & 0.511 & 0.468 \\
\hline$F S \cap I E T$ & 0.237 & 0.614 & 0.296 & 0.486 \\
\hline TT $\cap$ IET & $\underline{0.495}$ & $\underline{0.311}$ & 0.396 & 0.429 \\
\hline
\end{tabular}

The above results with "_" mean that the interaction results are a twofactor enhancement, and the rest are nonlinear enhancement. When $\mathrm{q}\left(\mathrm{K}_{1} \cap \mathrm{K}_{2}\right)>\operatorname{Max}\left[\mathrm{q}\left(\mathrm{K}_{1}\right), \mathrm{q}\left(\mathrm{K}_{2}\right)\right.$, it is a two-factor enhancement relationship, and when $\mathrm{q}\left(\mathrm{K}_{1} \cap \mathrm{K}_{2}\right)>\mathrm{q}\left(\mathrm{K}_{1}\right)+\mathrm{q}\left(\mathrm{K}_{2}\right)$, it is a nonlinear enhancement relationship

the most significant impact on the determinants of regional carbon emission spatial differentiation, and their interaction factor statistics $q$ values are above 0.8 . This shows that the four critical interactive factors of energy consumption level, technology development level, economic development level, and urbanization level have significant multiple spatial superposition interaction on the determinant of spatial differentiation of carbon emissions. Among them, the $q$ values of interaction factor statistics of UR $\cap$ ECI and ECI $\cap$ IET are always at the forefront, which indicates that the level of energy consumption, urbanization, and opening to the outside world has a significant impact on the spatial differentiation pattern of regional carbon emissions, which is consistent with the research results of Zhao and $\mathrm{Wu}$ (2018). The $q$ value of the interaction factor statistic of ECI $\cap$ TT increased from 0.852 in 2005 to 0.925 in 2019 , indicating that the interaction between regional energy consumption level and technological development level on the spatial differentiation pattern of regional carbon emissions has a significant multiple spatial superposition interaction effects, and the interaction is increasing. This shows that when detecting the influence degree of different driving factors on the spatial differentiation pattern of regional carbon emissions, we 
should not only consider the influence degree of a single factor but also combine the influence degree of interaction between two factors and the influence of change trend on the spatial differentiation pattern of carbon emissions, to detect the influence of different driving factors on the spatial differentiation pattern of carbon emissions in more detail and comprehensively.

\section{Conclusions and policy recommendations}

\section{Conclusions}

This paper first estimates the carbon emissions of the eight economic regions from 2005 to 2019 from the perspective of terminal energy consumption; secondly, from the standpoint of GIS visualization, this paper objectively analyzes the spatial differences of carbon emissions in the eight economic regions, decomposes the overall differences, and finds out the main reasons for the overall differences in the different areas; finally, we identify the main driving factors that affect the differences of carbon emissions in the eight economic regions and detect the changing trend of the intensity value of the main driving factors. Through in-depth analysis of the mechanism of each driving factor, we focus on the multiple superimposed interaction effects of key interaction factors on the spatial differentiation of regional carbon emissions. The results show the following:

(1) The spatial distribution of carbon emissions shows a state of "more in the east and less in the west," which indicates the imbalance of carbon emission distribution in China and reflects the high matching degree between carbon emissions and GDP in China. Overall, China's overall carbon emissions trend from 2005 to 2019, with significant differences among provinces. Therefore, it is more comfortable to choose carbon emissions produced by the energy consumption as the measurement index when formulating emission reduction measures.

(2) The results of the Theil index show that the overall difference in regional carbon emissions is increasing in the study period, and the inter-regional difference is the main reason for the difference in regional carbon emissions. The contribution rate of inter-regional differences has risen from $55.8 \%$ in 2005 to $58.6 \%$ in 2019. The contribution rate of inter-regional differences in the ECER and SCER regions is more than $80 \%$. On the contrary, the contribution rate of intraregional difference has dropped from $44.2 \%$ in 2005 to $41.4 \%$ in 2019 . Compared with the traditional threezone division model, the eight economic regions are more conducive to formulating corresponding emission reduction measures according to the contribution of different regions, promoting the national carbon market's effective operation, and laying the foundation for the realization of carbon reduction target.

(3) The analysis results of Geodetector show that the level of energy consumption, technological development, and industrialization are the main driving factors affecting the spatial differentiation of regional carbon emission. Still, with the progress of technology and energy structure optimization, their decisive level decreases slightly. Under the constraint of the " 30.60 "double carbon goal, the decisive power of the green development level is slowly rising, which has become an external factor that cannot be ignored, affecting the spatial differentiation pattern of regional carbon emissions. The relationship between urbanization level and carbon emissions is inverted U-shaped. In the beginning, the improvement of urbanization level will increase regional carbon emissions. However, as the level of urbanization reaches a certain extent, it will promote the reduction of regional carbon emissions. The interaction results of each driving factor show nonlinear enhancement or two-factor enhancement, which indicates that the interaction of two factors will increase the explanatory power of the spatial differentiation pattern of carbon emissions.

\section{Policy recommendations}

Under the "30.60" dual carbon emission reduction target, different regions should follow the principle of "common but different" to share the overall emission reduction target, consider their objective development and carbon emission situation, and formulate targeted carbon emission reduction measures. Based on the above research, this paper puts forward the following policy recommendations:

(1) Give full play to the role of the government's "visible hand" in collaborative emission reduction in different regions, consider the high matching degree between regional carbon emissions and regional GDP, and formulate appropriate measures to encourage developed regions to give priority to reducing carbon emissions through energy transformation, industrial structure transformation, and low-carbon technology. And we should provide some subsidies to the underdeveloped areas to promote the development of energy-saving and emission reduction technology to reduce carbon emissions fundamentally.

(2) According to the decomposition results of the overall differences of carbon emissions in different regions, the differentiated emission reduction measures are realized. More stringent carbon emission reduction measures 
should be formulated for "key regions" with significant contributions from the different regions. More stringent emission reduction measures should be given in the national carbon emission allocation for the regions such as NEER, ECER, SCER, and NWER with significant inter-regional difference contribution. On the contrary, NCER, ERMRYR, ERMRYTR, and SWER regions with high intra-regional contribution should formulate emission reduction measures for different regions to narrow the differences in carbon emission reduction among areas in the region and reduce the overall regional differences of carbon emission reduction.

(3) In China, carbon emissions are significant, especially in the middle reaches of the Yellow River. We should accelerate the coordinated development of technology, industrialization, and energy consumption. Those resource-based provinces with coal as the primary energy consumption should gradually transform from the extensive economic development model of high energy consumption and high emission to the development model of the low-carbon economy. Although the urbanization level and green development level have little impact on the spatial differentiation pattern of carbon emissions, they show an apparent upward trend. With the government's attention to the urban development level and green development, these two factors cannot be ignored when exploring the impact on the spatial differentiation pattern of carbon emissions. Therefore, to achieve China's " 30.60 " double carbon goal, we must reduce energy consumption, improve energy efficiency, and optimize the coordinated development of influencing factors such as technology level, economic development level, and energy consumption level as soon as possible to realize regional carbon emission reduction as soon as possible.

\section{Discussion}

The primary motivation of this study is to explore the differences in carbon emissions among China's eight economic regions and the temporal and spatial evolution characteristics of the spatial differentiation pattern of carbon emissions. Unlike previous studies, this paper can detect the impact of different factors on the spatial differentiation of regional carbon emissions from the perspective of single driving factors and detect the impact of the interaction of two driving factors on the spatial differentiation pattern carbon emissions.

This detection method can dynamically analyze the influence of a single driving factor from the time gradient and observe the multiple spatial superposition interaction effects between the key interaction factors. To clarify the differences and advantages of this study, the results are analyzed and compared with Liu et al. (2020), Chen et al. (2021a, b), Han et al. (2020), Zhao and Wu (2018), Yang et al. (2019), and Yang and Liu (2012). Since the research method of this paper is most similar to that of Zhao and Wu (2018), the conclusion of this paper is mainly compared with the research results of Zhao and $\mathrm{Wu}$ (2018) in detail.

\section{Differences}

Different from Liu et al. (2020 and Chen et al. (2021a, b), this paper not only selected eight primary fossil fuels: raw coal, coke, crude oil, kerosene, diesel oil, gasoline, fuel oil, and natural gas. This paper refers to Han et al.'s (2020) study and subdivides the energy consumption in different regions into 17 main fossil fuel consumption types in more detail (see Table 1). This accounting method can more accurately calculate the carbon emission of primary energy consumption in different regions and better distinguish the carbon emission difference in different areas. Similar to the above research results, the overall carbon emissions of the eight economic areas vary greatly, and the reasons for the differences in carbon emissions in different regions are different.

Liu et al. (2020) selected six influencing factors: population, real GDP per capita, energy intensity, energy structure, industrial structure, and urbanization rate when exploring the causes of carbon emission differences in different regions, and the partial least square variable importance of project (PLS-VIP) method is used to analyze the factors affecting regional carbon emission differences. The results show that the population has the most significant impact on carbon emissions, per capita GDP, and energy structure. Similarly, Chen et al. (2019b) and Ouyang et al. (2020), respectively, explored the impact of environmental regulation on China's provincial and energy-intensive heavy industry. The research results show that upgrading industrial structures can strengthen environmental regulation and significantly inhibit carbon dioxide emissions. Ouyang et al. (2020) also adopted the PSM-DID method to introduce carbon trading, and the stability analysis results show that environmental regulation can effectively reduce carbon emissions from heavy industries. Chen et al. (2021a, b) selected six indicators such as energy efficiency, environmental regulation, industrial structure, population size, foreign trade, and energy consumption structure to analyze the factors affecting carbon emissions in combination with the GTWR-STIRPAT model. The research results show that the impact of population size and energy consumption structure on carbon emissions does not have temporal and spatial characteristics. However, the improvement of both will promote the increase of carbon emissions in most provinces of China.

This study believes that, in general, the level of energy consumption has the greatest decisive power on the spatial differentiation pattern of regional carbon emissions. With 
the continuous development of the region, the contribution rate of regional carbon emission influencing factors is also changing greatly. From the perspective of time, the impact of energy consumption level, industrialization level, and technological progress level on the spatial differentiation pattern of regional carbon emissions shows a downward trend, while the contribution rate of urbanization level, economic development level, opening-up level, and green development level to the spatial differentiation pattern of regional carbon emissions gradually increases. Due to the different indicators and methods used by scholars, the contribution rates of different influencing factors are quite different. In addition to selecting common indicators affecting carbon emissions, this paper considers the relevant contents of China's development stage and the " 30.60 " double carbon target and also selects regional carbon sink indicators to measure the level of regional green development. Combined with the research index selection and research results analysis of Zhao and Wu (2018), Yang et al. (2019), and Yang and Liu (2012), it is considered that this research conclusion is more in line with the current situation of China's future low-carbon development.The results of this study show that the level of urbanization has little impact on the spatial differentiation pattern of regional carbon emissions and tends to be more stable from 2005 to 2010. However, the urbanization level jumped from 0.765 in 2010 to 0.127 in 2015, and the impact on regional carbon emissions has been significantly improved, which is closely related to the acceleration of urbanization in China during this period. The research conclusion is consistent with the research conclusion of Zhao and Wu (2018). The impact of industrialization level on carbon emissions began to show a downward trend after 2010, which is closely related to China's development stage and the rise of the proportion of service industry. The research conclusion is similar to that of Zhao and $\mathrm{Wu}$ (2018). According to the research of Yang et al. (2019), the impact of industrialization level on the spatial pattern of carbon emissions generally shows a downward trend, and the detection results of this paper also show that the impact of industrialization level on regional carbon emissions shows a fluctuating downward trend. In September 2020, President $\mathrm{Xi}$ Jinping proposed that forest volume should be one of the specific objectives of the " 30.60 " double carbon target. In order to further study how to allocate regional carbon quotas fairly and how to reduce the exploitation awareness of restrictive carbon emission rights, this paper introduces the carbon sink capacity into the study of the driving factors affecting regional carbon emissions, which also provides a basis for improving the rationality of regional carbon emission rights allocation. Combined with the previous research literature, this paper introduces forest stock as an index to measure carbon sink capacity and discusses the impact of green development level on carbon emission. The results show that although the regional green development level has little impact on regional carbon emissions, the statistical value $q$ of this factor increases greatly, indicating that with the attention of various regions to environmental problems, the decisive power of regional green development level on the spatial differentiation pattern of regional carbon emissions gradually increases.To sum up, different influencing factors contribute to regional carbon emission differences due to different index selection, research methods, research period, research regions, and so on.

\section{Advantages}

The main advantages of this paper are as follows:

Firstly, the carbon emission measurement methods of fossil fuel consumption are subdivided into 17 primary fossil fuels, which makes the carbon emission measurement results of different regions more accurate and is conducive to a more precise observation of the difference in carbon emission in different regions.

Secondly, when selecting indicators, according to a large number of previous studies, the indicators with significant influence are chosen, and the selection of indicators is more representative. At the same time, according to China's newly proposed " 30.60 " double carbon goal, the influencing factors of regional carbon sink capacity are introduced, and the influence of this factor is detected. This paper's research perspective and conclusion are closer to China's economic development and the "30.60" double carbon goal planning.

Finally, this study selects the geographic detector method for influencing factors analysis compared with classical statistical methods such as the Kaya equation, IPAT model, and STIRPAT model. The main advantages of this method are two aspects: On the one hand, it does not need to make pre-determined assumptions about the sample distribution and has an immune function for multicollinearity problems. On the other hand, it can accurately measure the determinant of single driving factors on carbon emissions and analyze the impact of interactive factors on carbon emissions. The interactive effect breaks the traditional measurement model, which is limited to variable multiplication and can more honestly and accurately detect the relationship between variables. Therefore, combined with the " 30.60 " double carbon goal, this paper decomposes and analyzes the carbon emission differences of China's eight economic regions by using the geographic detector method and finds out the main driving factors affecting regional carbon emission and the interaction between driving factors, which can better provide targeted suggestions for regional carbon emission reduction in the future.

Due to space and data acquisition limitations, this paper still has the following aspects of being optimized: (1) In calculating green development levels in different regions, only 
forest carbon sink is selected. Marine carbon sink and other factors are not considered. Hence, the calculation results are not accurate enough. (2) Only the eigenvalues of spatial differentiation in 2005, 2010, 2015, and 2019 are used to analyze the influence of driving factors, which cannot fully reflect the detailed change trend of spatial differentiation determinants of different driving factors in time series. (3) Limited by the inconsistency of statistical caliber, the impact of the carbon trading volume of eight carbon trading pilot markets (Beijing, Shanghai, Tianjin, Chongqing, Hubei, Guangdong, Shenzhen, and Fujian) from 2013 to 2019 on regional carbon emissions was not considered.To more accurately explore the causes and trends of carbon emission differences in different regions, the next step will be a more in-depth study from the above points.

Author contribution Conceptualization: Yuan Zhang, Zhen Yu. Data curation: Zhen Yu. Formal analysis: Yuan Zhang. Methodology: Yuan Zhang, Zhen Yu.Validation: Yuan Zhang, Juan Zhang.Writing - original draft: Yuan Zhang. Writing - review and editing: Yuan Zhang, Zhen Yu, Juan Zhang.

Data availability The datasets generated and analyzed during the current study are not publicly available but are available from the corresponding author on reasonable request.

\section{Declarations}

Ethics approval and consent to participate Not applicable.

Consent for publication Not applicable.

Competing interest The authors declare no competing interests.

\section{References}

Anders L, Lars T (2021) Accounting for all territorial emissions and sinks is important for development of climate mitigation policies. Carbon Balance Manag 16:10

Ang BW (2005) The LMDI approach to decomposition analysis: a practical guide. Energ Policy 33:867-871

Ang BW, Su B, Wang H (2016) A spatial-temporal decomposition approach to performance assessment in energy and emissions. Energ Econ 60:112-121

Bianco V, Cascetta F, Marino A, Nardini S (2019) Understanding energy consumption and carbon emissions in Europe: a focus on inequality issues. Energy 170:120-130

Danish Burcu O, Recep U (2021) An empirical investigation of nuclear energy consumption and carbon dioxide (CO2) emission in India: Bridging IPAT and EKC hypotheses. Nucl Eng Technol 53(6):2056-2065

Cantore N, Padilla E (2010) Equality and CO2 emissions distribution in climate change integrated assessment modelling. Energy $35: 298-313$
Chang CP, Dong MY, Sui B, Chu Y (2019) Driving forces of global carbon emissions: from time- and spatial-dynamic perspectives. Econ Model 77:70-80

Chen JD, Xu C, Cui LB et al (2018) Driving factors of CO2 emissions and inequality characteristics in China: a combined decomposition approach. Energ Econ 78:589-597

Chen C, Zhao T, Yuan R, Kong YC (2019) A spatial-temporal decomposition analysis of China's carbon intensity from the economic perspective. J Clean Prod 215:557-569

Chen SY, Jin H, Lu YL (2019b) Impact of urbanization on CO2 emissions and energy consumption structure: a panel data analysis for Chinese prefecture-level cities. Struct Chang Econ Dyn 49:107-119

Chen X, Chen YE, Chang CP (2019c) The effects of environmental regulation and industrial structure on carbon dioxide emission: a nonlinear investigation. Environ Sci Pollut Res 26(29):30252-30267

Chen F, Yu HC, Bian ZF, Yi DY (2021a) How to handles the crisis of coal industry in China under the vision of carbon neutrality. J China Coal Soc 46(06): 1808-1820

Chen JQ, Lian XY, Su HN et al (2021b) Analysis of China's carbon emission driving factors based on the perspective of eight major economic regions. Environ Sci Pollut Res 28(7):8181-8204

Clarke-Sather A, Qu JS et al (2011) Carbon inequality at the subnational scale: a case study of provincial-level inequality in $\mathrm{CO}_{2}$ emissions in China 1997-2007. Energ Policy 39:5420-5428

Cowell FA (1980) On the structure of additive inequality measures. Rev Econ Stud 47(3):521-531

Cui Y, Khan SU, Deng Y, Zhao MJ (2021) Regional difference decomposition and its spatiotemporal dynamic evolution of Chinese agricultural carbon emission: considering carbon sink effect. Environ Sci Pollut R 28(29):1-20

Deng X, Xie J, Teng F (2021) What is carbon neutrality? Clim Chang Res 17:107-113

Duro JA, Padilla E (2006) International inequalities in per capita CO2 emissions: a decomposition methodology by Kaya factors. Energ Econ 28:170-187

Eduardo P, Naijela S, Diogo F et al (2021) The drivers of energy-related $\mathrm{CO}$ emissions in Brazil: a regional application of the STIRPAT model $_{2}$. Environ Sci Pollut R 28(37):51745-51762

Fan Y, Liu LC, Wu G et al (2007) Changes in carbon intensity in China: empirical findings from 1980-2003. Ecol Econ 62:683-691

Gao CX, Tao SM, He YY et al (2021) Effect of population migration on spatial carbon emission transfers in China. Energy Policy 156:112450

Han YY, Pi HJ, Shi ZN et al (2020) Study on measurement and influencing factors of industrial $\mathrm{CO} 2$ emission in Beijing-TianjinHebei Region. World Reg Stud 29(1):140-147

Hoekstra R, van den Bergh JCJM (2003) Comparing structural decomposition analysis and index. Energ Econ 25:39-64

Kou JN, Zhang R (2021) Who will continue to lead global climate governance in the post COVID-19 Era -The EU's decline and counterattack. J China Univ Geosci (Social Sciences Edition) 21:87-104

Li L, Hong XF, Peng K (2019) A spatial panel analysis of carbon emissions, economic growth and high-technology industry in China. Struct Chang Econ Dyn 49:83-92

Li Y, Yang XD, Ran QY, Wu HT et al (2021) Energy structure, digital economy, and carbon emissions: evidence from China. Environ Sci Pollut Res Int 28(45):64606-64629

Liu N, Ma ZJ, Kang JD (2017) A regional analysis of carbon intensities of electricity generation in China. Energ Econ 67:268-277

Liu N, Ma ZJ, Kang JD, Su B (2019) A multi-region multi-sector decomposition and attribution analysis of aggregate carbon intensity in China from 2000 to 2015. Energ Policy 129:410-421

Liu XZ, Yang X, Guo RX (2020) Regional differences in fossil energyrelated carbon emissions in China's eight economic regions: 
based on the Theil index and PLS-VIP method. Sustainability 12(7):2576

Liu JG, Li SJ, Ji Q (2021a) Regional differences and driving factors analysis of carbon emission intensity from transport sector in China. Energy 224:120178

Liu XL, Cui LL, Li B, Du WX (2021b) Research on the high-quality development path of China's energy industry under the target of carbon neutralization. J Beijing Inst Technol (Social Sciences Edition) $23: 1-8$

Liu WX, Xu RF, Deng Y et al (2021c) Dynamic relationships, regional differences, and driving mechanisms between economic development and carbon emissions from the farming industry: empirical evidence from rural China. Int J Environ Res Public Health 18(5):2257

Ma XJ, Wang CX, Dong BY et al (2019) Carbon emissions from energy consumption in China: its measurement and driving factors. Sci Total Environ 648:1411-1420

Majeed MT, Khan S, Tahir T (2020) Analytical tool for unpacking the driving forces of environmental impact: an IPAT analysis of Pakistan. GeoJournal 1-13.

Nam E, Jin TY (2021) Mitigating carbon emissions by energy transition, energy efficiency, and electrification: difference between regulation indicators and empirical data. J Clean Prod 300

Ouyang XL, Fang XM, Cao Y, Sun CW (2020) Factors behind CO2 emission reduction in Chinese heavy industries: do environmental regulations matter? Energy Policy 145:111765

Ridge SM, McKinley GA (2021) Ocean carbon uptake under aggressive emission mitigation. Biogeosciences 18(8):2711-2725

Roberto P, Matteo V, Gherardo C (2021) Combined effects of natural disturbances and management on forest carbon sequestration: the case of Vaia storm in Italy. Ann Forest Sci 78(2):1-18

Rong Y, Rodrigues JFD, Behrens P (2019) Driving forces of household carbon emissions in China: A spatial decomposition analysis. J Clean Prod 233:932-945

Salvia M, Reckien D, Pietrapertosa F et al (2021) Will climate mitigation ambitions lead to carbon neutrality? An analysis of the local-level plans of 327 cities in the EU. Renew Sustain Energy Rev 135:110253

Shan YL, Guan DB, Liu JH, Mi ZF, Liu Z et al (2017) Methodology and applications of city level $\mathrm{CO} 2$ emission accounts in China. $\mathrm{J}$ Clean Prod 161:1215-1225

Smriti M (2020) How China could be carbon neutral by mid-century. Nature 586(7830):482-483

Sun ZQ, Wang GJ, Chen YN (2015) Analysis on the uncertainty of carbon emission accounting Based on energy balance sheet. Ecol Econ 31:33-38

Vaninsky A (2014) Factorial decomposition of CO2 emissions: a generalized Divisia index approach. Energ Econ 45:389-400

Wang M, Feng C (2018) Investigating the drivers of energy-related $\mathrm{CO} 2$ emissions in China's industrial sector: from regional and provincial perspectives. Struct Chang Econ Dyn 46:136-147
Wang JF, Hu Y (2012) Environmental health risk detection with Geogdetector. Environ Model Softw 33:114-115

Wang JF, Xu CD (2017) Geodetector: principle and prospective. Acta Geogr Sin 72:116-134

Wang C, Zhang YX (2020) Implementation pathway and policy system of carbon neutrality vision. Chin J Environ Manag 12:58-64

Wang H, Zhou P (2018) Assessing global CO2 emission inequality from consumption perspective: An index decomposition analysis. Ecol Econ 154:257-271

Wang H, Ang BW, Su B (2017) Assessing drivers of economy-wide energy use and emissions: IDA versus SDA - ScienceDirect. Energ Policy 107:585-599

Wang J, Hu MM et al (2018) An empirical spatiotemporal decomposition analysis of carbon intensity in China's industrial sector. J Clean Prod 195:133-144

Wang JF, Li XH et al (2010) Geographical detectors-based health risk assessment and its application in the neural tube defects study of the Heshun region. China. Int J Geogr Inf Sci 24(1):107-127

Wang ZJ, Yin JJ, Pu JB et al (2020) Flux and influencing factors of $\mathrm{CO} 2$ outgassing in a karst spring-fed creek: implications for carbonate weathering-related carbon sink assessment. J Hydrol 596

Yang Q, Liu HJ (2012) Regional difference decomposition and influence factors of China's carbon dioxide emissions. J Quant Tech Econ 29(05):36-49+148

Yang C, Wu LJ, Li JF, Huang TN (2019) Distribution of carbon emission rights in China based on equity perspective. Resour Sci 41:1801-1813

Yang Y, Yu HY, Lu G et al (2020) Interview on the unprecedented changes of energy geopolitics and national energy security. J Nat Resour 35:2803-2820

Yang XH, Jia Z, Yang ZM, Yuan XY (2021) The effects of technological factors on carbon emissions from various sectors in China- $\mathrm{a}$ spatial perspective. J Clean Prod 301:126949

Zhang YG (2010) Supply-side structural effect on carbon emissions in China. Energ Econ 32:186-193

Zhang Y, Yu Z, Zhang J (2021) Analysis of carbon emission performance and regional differences in China's eight economic regions: based on the super-efficiency SBM model and the Theil index. PloS One 16(5):e0250994

Zhang XP, Zhang HN, Zhao CH, Yuan JH (2019) Carbon emission intensity of electricity generation in Belt and Road initiative countries: a benchmarking analysis. Environ Sci Pollut Res 26(15):15057-15068

Zhao LD, Wu D (2018) Carbon emission accounting and spatial heterogeneity pattern of China's energy supply side. China Popul Resour Environ 28:48-58

Zheng JL, Mi ZF et al (2019) Regional development and carbon emissions in China. Energy Econ 81:25-36

Publisher's note Springer Nature remains neutral with regard to jurisdictional claims in published maps and institutional affiliations. 